\title{
Systematic Literature Review: Etnomatematika Kearifan Lokal Budaya Sasak
}

\author{
Muhammad Turmuzi ${ }^{1}$, I Gusti Putu Sudiarta ${ }^{2}$, I Gusti Putu Suharta ${ }^{3}$ \\ 1,2,3 Universitas Pendidikan Ganesha, Singaraja Bali \\ Jl. Udayana No 11, Singaraja Bali, Indonesia \\ tur.muzi@yahoo.co.id
}

\begin{abstract}
The purpose of this study was to determine the mathematical concepts related to the ethnomathematics of local wisdom of Sasak Culture. This research is a Systematic Literature Review conducted by identifying, reviewing, researching, and discussing all available research. The design used in this study is to summarize, review, and analyze 10 articles discussing the Ethnomathematics of Sasak Culture with details of one article published in a reputable journal Q2 and the rest in the Sinta accredited National Journal. The search for these articles is carried out through online journals such as journal articles from Google Schoolar, Research Gate, SINTA, DOAJ, and Scopus. The conclusion of this research is the findings of concepts related to the mathematical ethnomathematics of local wisdom of the Sasak Culture, which consists of Flat Plane Geometry, Geometric Space Constructing, Geometric Conceptions, Measurement, Volume of Rotating Objects, Perimeter and Area of Flat Planes.
\end{abstract}

Keywords: Systematic Literature Review, Ethnomathematics, Sasak Culture

\begin{abstract}
Abstrak
Tujuan penelitian ini adalah untuk mengetahui konsep-konsep matematika yang berhubungan dengan Etnomatematika kearifan lokal Budaya Sasak. Penelitian ini merupakan Systematic Literature Review yang dilakukan dengan mengidentifikasi, mengkaji, mengevaluasi, serta menafsirkan semua penelitian yang tersedia. Desain yang digunakan dalam penelitian ini adalah merangkum, mereview, dan menganalisis 10 artikel dengan lingkup pembahasan Etnomatematika Budaya Sasak dengan rincian satu artikel yang diterbitkan di jurnal bereputasi Q2 dan sisanya dalam Jurnal Nasional terakreditasi Sinta. Penelusuran artikel-artikel ini dilakukan melaui Jurnal online seperti artikel jurnal dari Google Schoolar, Research Gate, SINTA, DOAJ, dan Scopus. Kesimpulan penelitian ini adalah temuan konsep-konsep matematika yang terkait Etnomatematika kearifan lokal Budaya Sasak adalah terdiri dari Geometri Bidang Datar, Bangun Ruang Geometri, Konsep Transformasi geometri, Pengukuran, Volume Benda Putar, Keliling dan Luas Bangun Bidang Datar.
\end{abstract}

Kata kunci: Systematic Literature Review, Etnomatematika, Budaya Sasak

Copyright (c) 2022 Muhammad Turmuzi, I Gusti Putu Sudiarta, I Gusti Putu Suharta

$\square$ Corresponding author: Muhammad Turmuzi

Email Address: tur.muzi@yahoo.co.id (Jl. Udayana No 11, Singaraja Bali)

Received 11 December 2021, Accepted 23 December 2021, Published 19 January 2022

\section{PENDAHULUAN}

Pendidikan bertujuan untuk mempersiapkan peserta didik atau sumber daya manusia untuk menghadapi persaingan dalam hidup dan mencari nafkah (bekerja dan menciptakan lapangan kerja). (Fadillah et al., 2021, p. 138). Sumber daya manusia yang berkualitas akan berpengaruh terhadap kemajuan bangsa terutama dalam hal penguasaan ilmu pengetahuan dan teknologi. Penguasaan IPTEK yang baik akan dapat meningkatkan daya saing dan kemajuan bangsa bila disandingkan dengan negara lain. Penguasaan IPTEK tidak terlepas dari penguasaan konsep matematika yang dimiliki oleh peserta didik. Penguasaan Konsep matematika peserta didik dapat dilihat dari berbagai ajang olimpiade matematika, baik dalam level Nasional maupun Internasional. Hasil studi TIMSS dan PISA menempatkan Indonesia pada peringkat yang rendah (dibawah rata-rata). Hal ini disebabkan 
karena kurangnya kemampuan matematika siswa dalam menyelesaikan soal penalaran \& pemecahan masalah akibat kurangnya pemberian porsi menalar dan memecahkan masalah pada materi ajar dan soal-soal latihan kepada siswa. Selain itu fakta di masyarakat menunjukkan bahwa banyak siswa yang gagal memperoleh nilai matematika yang sebenarnya, karena hanya terpacu untuk memenuhi target nilai ujian saja. Hal ini mengakibatkan kehawatiran akan kurang mampunya siswa dalam menerapkan matematika untuk menyelesaikan masalah dalam kehidupan sehari-hari.(Rachmawati, 2012, p. 1).

Adanya permasalahan tersebut dan tambahan teori bahwa pengetahuan matematika juga dapat diperoleh di luar sistem terstruktur pembelajaran matematika seperti sekolah. Kita sudah semestinya mengupayakan berbagai alternatif dan inovasi dalam rangka meningkatkan kemampuan matematika peserta didik. Salah satu kuncinya adalah perbaikan proses pembelajaran di sekolah, khususnya dengan meningkatan porsi menalar, memecahkan masalah, berargumentasi dan berkomunikasi melalui materi ajar yang lebih kontekstual. Untuk mengaitkan materi matematika yang kontekstual dapat dilakukan dengan berbagai cara seperti pembelajaran matematika yang realistik (PMR), pembelajaran matematika yang kontekstual atau dengan mengaitkan matematika dengan budaya setempat yang lebih dikenal dengan nama Etnomatematika. Menurut Hardiarti, (2017, p. 99) matematika dan budaya adalah sesuatu yang tidak bisa dihindari dalam kehidupan sehari-hari, karena budaya merupakan kesatuan yang utuh dan menyeluruh, berlaku dalam suatu masyarakat sedangkan matematika merupakan pengetahuan yang digunakan manusia dalam menyelesaikan masalah seharihari. Namun terkadang matematika dan budaya dianggap sebagai sesuatu yang terpisah dan tidak berkaitan. Hal berbeda diungkapkan oleh (Buyung \& Hendriana, 2020, p. 2) bahwa lingkungan sebagai tempat berinteraksi sehari-hari serta siswa selalu berada dan dipengaruhi oleh kebudayaan yang ada dilingkungan tersebut. Sedangkan menurut Sudiarta (2008, p. 12) menjelaskan tentang domain penelitian pendidikan matematika yang penting untuk diperhatikan salah satunya adalah berkaitan dengan aspek kompetensi matematika, kemampuan intelektual dan pengalaman matematika siswa.

Bishop (1994) menyatakan bahwa matematika merupakan suatu bentuk budaya. Matematika sebagai bentuk budaya, sesungguhnya telah terintegrasi dalam seluruh aspek kehidupan masyarakat. Selanjutnya (Pinxten, 1994) menyatakan bahwa pada hakekatnya, matematika merupakan teknologi simbolis yang tumbuh pada keterampilan atau aktivitas lingkungan yang bersifat budaya. Dengan demikian matematika seseorang dipengaruhi oleh latar budayanya, karena yang mereka lakukan berdasarkan apa yang mereka lihat dan rasakan. Budaya akan mempengaruhi perilaku individu dan mempunya peran yang besar pada perkembangan pemahaman individual, termasuk pembelajaran matematika. Matematika berasal dari cara, gaya, dan teknik yang dikembangkan oleh manusia untuk merespon lingkungan seperti mencari penjelasan, pemahaman, pengalaman, dan solusi terhadap fenomena di sekitarnya. (Prahmana et al., 2021, p. 93). Istilah etnomatematika diperkenalkan oleh D’Ambrosio seorang matematikawan Brazil pada tahun 1977. Secara bahasa, awalan "ethno" 
Systematic Literature Review: Etnomatematika Kearifan Lokal Budaya Sasak, Muhammad Turmuzi, I Gusti Putu Sudiarta, I Gusti Putu Suharta

diartikan sebagai sesuatu yang sangat luas yang mengacu pada konteks sosial budaya, termasuk bahasa, jargon, kode perilaku, mitos dan simbol. Kata dasar "mathema" cenderung berarti menjelaskan, mengetahui, memahami, dan melakukan kegiatan seperti pengkodean, mengukur, mengklarifikasi, menyimpulkan, dan pemodelan. Akhiran "tics" berasal dari katatechne dan bermakna sama seperti teknik. (Ascher \& Ambrosio, 1994, p. 449).

Salah satu tujuan pembelajaran matematika adalah mempersiapkan siswa untuk menggunakan matematika dan pola pikir matematis dalam kehidupan sehari-hari. (Supiyati et al., 2019), (Soedjadi, 200). Menurut (Barta \& Shockey, 2006) etnomatematika adalah representasi kompleks dan dinamis yang menggambarkan pengaruh budaya penggunaan matematika dalam penerapannya. Dalam pembelajaran matematika di sekolah selama ini siswa masih menganggap matematika itu sulit, terlalu abstrak, banyak rumus dan lain sebagainya, hal ini dikarenakan pembelajaran matematika di sekolah terlalu formal dan tidak sesuai dengan apa yang dialami siswa dalam kehidupan sehari-hari. Oleh karena itu, diperlukan penelitian lebih lanjut untuk menggali budaya-budaya yang ada di sekitar kita untuk menemukan konsep-konsep matematika yang konkrit sehingga konsep-konsep tersebut dapat diterapkan dalam pembelajaran matematika sekolah.

Selain alasan di atas akibat pengaruh era globalisasi saat ini, masyarakat Indonesia terutama peserta didik sudah secara perlahan mulai meninggalkan nilai-nilai luhur budaya bangsa, sehingga perlu memantapkan nilai-nilai budaya dalam pembelajaran matematika di sekolah. Menjurut (Rahayu et al., 2020, p. 17) Indonesia merupakan Negara yang terkenal dengan keanekaragaman budayanya. Seiring dengan perkembangan zaman, budaya-budaya Indonesia mulai punah. Tidak terkecuali, kehidupan anak-anak pun berubah, generasi yang baru dan akan datang cenderung tidak mengenal budaya mereka sendiri contohnya seperti budaya kain tenun. Mereka cenderung lebih mengenal produk pakaian luar negeri yang berbau "kekinian" dibandingkan produk-produk yang memanfaatkan kain tenun khas Indonesia dikarenakan pengaruh perkembangan zaman lebih mendominasi. Jika hal ini terjadi, tidak menutup kemungkinan bahwa nantinya budaya kita sendiri yang akan punah secara perlahan-lahan. Untuk itu diperlukan suatu upaya mengingatkan kembali atau semakin mendekatkan orang Indonesia khususnya siswa dengan budayanya sendiri, upaya tersebut dapat ditempuh melalui pendidikan, salah satunya pendidikan matematika.

Dari beberapa pendapat tersebut tampak bahwa dalam pembelajaran matematika di sekolah terdapat kecenderungan untuk menggali pengetahuan awal siswa harus dimulai dengan mengaitkan matematika formal dengan pengalaman siswa dalam kehidupan sehari-hari melaui budaya tempat tinggal mereka. Oleh karena itu, perlu dilakukan analisis terhadap studi-studi terdahulu terkait etnomatematika. Dalam penelitian ini difokuskan untuk menggali lebih dalam tentang adat budaya masyarakat Sasak terkait dengan perhitungan, pengukuran, pemodelan, perancangan khususnya yang berkaitan dengan bangunan tradisional masyarakat Sasak. Indonesia yang dikenal dengan seribu pulau yang memiliki beragam budaya, salah satunya adalah budaya sasak. Budaya sasak adalah budaya yang berasal dari pulau Lombok, Nusa Tenggara Barat. Masyarakat Lombok masih sangat kental 
dengan kebudayaan yang diwariskan oleh nenek moyang mereka baik dari aspek bangunan, tradisi, kesenian, kerajinan, bahkan dari makanan masih bersifat tradisional. Menurut (Rosa \& Clark, 2011), etnomatematika adalah penerapan keterampilan matematika, ide, prosedur, dan praktik yang diterapkan di masa lalu oleh anggota kelompok budaya tertentu dalam konteks yang berbeda, yang sering digunakan saat ini dalam konteks hari ini. Diharapkan berdasarkan temuan penelitian ini dapat menjadi acuan bagi guru dan pemerhati pembelajaran matematika agar dapat membuat buku ajar dan menggunakan budaya lokal khususnya budaya Sasak sebagai sumber pembelajaran matematika di sekolah, sehingga pembelajaran matematika lebih menarik dan bermakna bagi siswa. Dari uraian di atas maka fokus permasalahan dalam penelitian ini adalah bagaimanakah hasil Systematic Literature Review (SLR) terhadap konsep-konsep matematika terkait dengan kearifan lokal budaya Sasak?. Sedangkan tujuan penelitian ini adalah melalui Systematic Literature Review (SLR) dapat diketahui konsep-konsep matematika yang berhubungan dengan Etnomatematika kearifan lokal Budaya sasak.

\section{METODE}

Penelitian ini merupakan Systematic Literature Review (SLR). Systematic Literature Review (SLR-Tinjauan Pustaka Sistematis) merupakan metode literature review yang mengidentifikasi, menilai, dan menginterpretasi temuan-temuan pada suatu topik penelitian untuk menjawab pertanyaan penelitian (research question) yang telah ditetapkan sebelumnya. (Aliyah \& Mulawarman, 2020, p. 211). Systematic Literature Review (SLR) ini dilakukan dengan mengidentifikasi, mengkaji, mengevaluasi, serta menafsirkan semua penelitian yang tersedia. Dengan metode ini peneliti melakukan reviu dan mengidentifikasi jurna-jurnal secara terstruktur yang pada setiap prosesnya mengikuti langkah-langkah yang telah ditetapkan. (Triandini et al., 2019), (Putra \& Afrilia, 2020, p. 112). Desain yang digunakan dalam penelitian ini adalah merangkum, mereview, dan menganalisis beberapa penelitian yang menggunakan Etnomatematika kearifan lokal (local wisdom) Budaya Sasak sebagai tema penelitian melalui penelusuran dari berbagai sumber. Untuk menyelesaikan penelitian ini, peneliti mengumpulkan artikel jurnal dari Google Schoolar, Research Gate, SINTA, DOAJ, dan Scopus. Kata kuncinya adalah Etnomatematika kearifan lokal (local wisdom) Budaya Sasak. Artikel yang dikumpulkan adalah artikel yang dipublikasikan dalam rentang waktu 2016 hingga 2021.

Dari hasil penelusuran artikel ditemukan 10 artikel dengan lingkup pembahasan Etnomatematika Budaya Sasak dengan rincian satu artikel yang diterbitkan di jurnal bereputasi Q2 dan sisanya Jurnal Nasional terakreditasi Sinta. Metode atau pendekatan penelitian pada artikel-artikel ini sebagian besar merupakan penelitian dengan pendekatan kualitatif dengan model etnografi, yaitu sebanyak 5 artikel, 2 artikel dengan metode penelitian eksploratif, 1 artikel dengan metode kualitatif verifikatif, 1 artikel dengan metode Penelitian kualitatif menggunakan jenis penelitian studi multi situs dan 1 artikel dengan metode kajian literatur. Dari artikel-artikel tersebut selanjutnya di analisis untuk melihat konsep-konsep matematika yang terkait dengan Budaya Sasak. Langkah awal yang dilakukan dalam penelitian ini yaitu menentukan masalah, kemudian melakukan penelusuran data 
Systematic Literature Review: Etnomatematika Kearifan Lokal Budaya Sasak, Muhammad Turmuzi, I Gusti Putu Sudiarta, I Gusti Putu Suharta

penelitian melalui jurnal elektronik di google scholar dengan mengumpulkan 10 artikel yang relevan guna diambil datanya.

\section{HASIL DAN DISKUSI}

Dari hasil penelusuran artikel, peneliti menemukan masing-masing satu artikel yang publish di Jurnal bereputasi Q2 dan sisanya di Jurnal Nasional terakreditasi Sinta. Tabel 1 menjelaskan artikel yang terkait dengan nama penulis, tahun terbit, pertanyaan penelitian dan metode penelitian yang digunakan.

Tabel 1. Tahun Terbit Artikel dan Pertanyaan Penelitian

\begin{tabular}{|c|c|c|c|c|}
\hline No & Nama Penulis & Tahun & Pertanyaan Penelitian & Metode Penelitian \\
\hline 1 & $\begin{array}{l}\text { Sri Supiyati, Farida } \\
\text { Hanum, Jailani }\end{array}$ & 2019 & $\begin{array}{l}\text { Bagaimana eksplorasi lebih } \\
\text { lanjut tentang adat } \\
\text { masyarakat sasak terkait } \\
\text { dengan perhitungan, } \\
\text { pengukuran, pemodelan, } \\
\text { perancangan khususnya yang } \\
\text { berkaitan dengan bangunan } \\
\text { tradisional masyarakat Sasak }\end{array}$ & $\begin{array}{l}\text { Pendekatan kualitatif } \\
\text { dengan model } \\
\text { etnografi }\end{array}$ \\
\hline 2 & $\begin{array}{l}\text { Sutarto, Intan Dwi } \\
\text { Hastuti, Sri Supiyati }\end{array}$ & 2021 & $\begin{array}{l}\text { Bagaimana mengeksplorasi } \\
\text { unsur transformasi geometri } \\
\text { tenun suku sasak Sukarara } \\
\text { Lombok Tengah menurut } \\
\text { sudut pandang } \\
\text { etnomatematika }\end{array}$ & $\begin{array}{l}\text { Penelitian kualitatif } \\
\text { dengan model } \\
\text { etnografi }\end{array}$ \\
\hline 3 & $\begin{array}{l}\text { Asri Fauzi1, Ulfa } \\
\text { Lu'luilmaknun }\end{array}$ & 2019 & $\begin{array}{l}\text { Apa sajakah unsur-unsur } \\
\text { matematika yang terkandung } \\
\text { di dalam permainan } \\
\text { tradisional dengklaq. }\end{array}$ & $\begin{array}{l}\text { Penelitian etnografi } \\
\text { dengan pendekatan } \\
\text { kualitatif }\end{array}$ \\
\hline 4 & Muh. Yazid & 2018 & $\begin{array}{l}\text { Bagaimana konsep } \\
\text { matematika dalam kehidupan } \\
\text { sehari-hari menggunakan } \\
\text { Etnomatematika masyarakat } \\
\text { Lombok yang tercermin } \\
\text { melalui berbagai hasil } \\
\text { aktivitas dan kreativitas } \\
\text { matematika yang dimiliki dan } \\
\text { berkembang di masyarakat } \\
\text { Lombok }\end{array}$ & Penelitian eksploratif \\
\hline 5 & $\begin{array}{l}\text { Asri Fauzi, Heri } \\
\text { Setiawan }\end{array}$ & 2020 & $\begin{array}{l}\text { Bagaimana konsep geometri } \\
\text { Sekolah Dasar yang terdapat } \\
\text { pada kerajinan tradisional } \\
\text { Sasak. }\end{array}$ & $\begin{array}{l}\text { Penelitian kualitatif } \\
\text { dengan pendekatan } \\
\text { etnografi }\end{array}$ \\
\hline 6 & $\begin{array}{l}\text { Sumayani, Zaenuri, Iwan } \\
\text { Junaedi }\end{array}$ & 2020 & $\begin{array}{l}\text { Bagaimana eksplorasi } \\
\text { konsep-konsep matematika }\end{array}$ & $\begin{array}{l}\text { Pendekatan kualitatif } \\
\text { dengan model }\end{array}$ \\
\hline
\end{tabular}




\begin{tabular}{|c|l|l|l|l|}
\hline & & & $\begin{array}{l}\text { tentang budaya atau adat } \\
\text { istiadat (adat) masyarakat } \\
\text { sasak terkait dengan makanan } \\
\text { tradisional. }\end{array}$ & etnografi \\
\hline 7 & $\begin{array}{l}\text { Nur Hardiani, } \\
\text { Susilahudin Putrawangsa }\end{array}$ & 2019 & $\begin{array}{l}\text { Bagaimana tradisi penalaran } \\
\text { dan bertindak matematis } \\
\text { masyarakat suku Sasak di } \\
\text { Pulau Lombok dalam } \\
\text { melakukan kegiatan } \\
\text { pengukuran volume serta } \\
\text { mengungkap potensi } \\
\text { pengintegrasiannya dalam } \\
\text { pembelajaran matematika. }\end{array}$ & Kualitatif verifikatif \\
\hline 8 & $\begin{array}{l}\text { Asri Fauzi, Aisa Nikmah } \\
\text { Rahmatih, Muhammad } \\
\text { Sobri, Radiusman, Arif } \\
\text { Widodo }\end{array}$ & 2020 & $\begin{array}{l}\text { Bagaimana hasil eksplorasi } \\
\text { etnomatematika budaya sasak } \\
\text { yang dapat dijadikan sebagai } \\
\text { sumber belajar matematika }\end{array}$ & $\begin{array}{l}\text { Penelitian kualitatif } \\
\text { eksplorasi dengan } \\
\text { pendekatan etnografi }\end{array}$ \\
\hline 9 & $\begin{array}{l}\text { Al Kusaeri, Muhamad } \\
\text { Habib Husnial Pardi }\end{array}$ & 2019 & $\begin{array}{l}\text { Objek matematika apa saja } \\
\text { yang dapat di identifikasi } \\
\text { dalam produk budaya } \\
\text { masyarakat di desa Kembang } \\
\text { Kerang Lombok Timur dan } \\
\text { implementasi pendekatan } \\
\text { etnomatematika dalam proses } \\
\text { pembelajaran matematika }\end{array}$ & $\begin{array}{l}\text { Penelitian kualitatif } \\
\text { menggunakan jenis } \\
\text { penelitian studi multi } \\
\text { situs }\end{array}$ \\
\hline 10 & Sri Supiyati & 2016 & $\begin{array}{l}\text { Bagaimana matematika dalam } \\
\text { perspektif Budaya Sasak }\end{array}$ & Kajian Literatur \\
\hline
\end{tabular}

Berdasarkan tabel 1 dapat dilihat bahwa tema atau judul penelitian semua berkaitan dengan Etnomatematika (local wisdom) Budaya Sasak. Tahun terbit artikel antara tahun 2018 sampai tahun 2021 dan hanya satu artikel yang terbit dalam tahun 2016 yaitu artikel yang ditulis oleh Sri Supiyati. Selanjutnya dari 10 artikel sebagian besar metode penelitiannya menggunakan metode kualitatif dengan pendekatan etnografi yaitu sebanyak 5 artikel, dua artikel menggunakan metode eksploratif, satu artikel menggunakan metode kualitatif verifikatif dan satu artikel menggunakan metode kajian literatur.

Penelitian etnografi dewasa ini menjadi penelitian dengan banyak peminat, terutama dalam penelitian-penelitian ilmu sosial humaniora serta dalam peneltian yang berkaitan denagn etnis dan budaya. Hal ini sejalan dengan pendapat (Windiani \& Nurul, 2016, p. 88) yang menyebutkan bahwa salah satu pendekatan penelitian kualitatif yang banyak dipilih peneliti dewasa ini adalah etnografi. Salah satu alasan tingginya peneliti memilih etnografi karena etnografi dipahami sebagai sesuatu yang secara given dimiliki peneliti. Peneliti dibayangkan dengan sangat mudah hanya dapat melukiskan suatu kelompok etnik. Padahal, tidak semudah itu, karena etnografi juga mempunyai kaidahnya yang harus diikuti, mempunyai beberapa tataran akademik yang harus dipilih, dan pada gilirannya dapat 
Systematic Literature Review: Etnomatematika Kearifan Lokal Budaya Sasak, Muhammad Turmuzi, I Gusti Putu Sudiarta, I Gusti Putu Suharta

menggunakan dalam penelitian dengan penuh bertanggung jawab. Pada sisi lain disebutkan bahwa tolok ukur etnografi menitikberatkan pada aspek kebudayaan yang melekat pada suatu sistem kemasyarakatan, termasuk dalam konteks yang paling besar adalah kebudayaan yang melekat pada suatu bangsa. Sampel sederhananya tentu melalui pelacakan atas kebudayaan lokalitas-lokalitas yang ada. (Kamarusdiana, 2019, p. 114).

Selanjutnya dari 10 artikel itu dibahas temuan konsep matematika yang ada dalam Budaya Sasak. Konsep matematika yang ditemukan beragam seperti yang terlihat pada tabel 2 .

Tabel 2. Hasil Analisis Meta Temuan Konsep Matematika Budaya Sasak

\begin{tabular}{|c|c|c|}
\hline Nama Penulis & Hasil Temuan Etnomatematika Budaya Sasak & Kesimpulan Penelitian \\
\hline $\begin{array}{l}\text { Sri Supiyati, } \\
\text { Farida Hanum, } \\
\text { Jailani }\end{array}$ & $\begin{array}{l}\text { - Sudut ada di setiap rumah, masjid, dan lumbung } \\
\text { - Potongan rumah dan masjid menjelaskan konsep } \\
\text { segitiga } \\
\text { - Dinding rumah dan dasar lumbung mejelaskan persegi } \\
\text { dan persegi panjang } \\
\text { - Ruang dalem bale, kubah lumbung menjelaskan } \\
\text { - } \text { konsep simetris } \\
\text { - Gunung pada pintu rumah dan pintu gerbang rumah } \\
\text { - Dinding rumah Gunung Rate merupakan trapezium } \\
\text { Atap rumah bale tani, bale bonter dan bale Gunung } \\
\text { Rate merupakan konsep Prisma }\end{array}$ & $\begin{array}{l}\text { Arsitektur Sasak } \\
\text { memiliki desain } \\
\text { konstruksi dan ornamen } \\
\text { yang berbeda untuk } \\
\text { menghadirkan bangunan } \\
\text { yang berfungsi dan } \\
\text { indah. Selain itu, bentuk } \\
\text { model yang unik } \\
\text { berbentuk geometris. } \\
\text { Secara tidak sengaja } \\
\text { masyarakat Sasak telah } \\
\text { mempraktikkan } \\
\text { matematika dalam } \\
\text { kehidupan sehari-hari. }\end{array}$ \\
\hline $\begin{array}{l}\text { Sutarto, Intan } \\
\text { Dwi Hastuti, } \\
\text { Sri Supiyati }\end{array}$ & $\begin{array}{l}\text { - Transformasi geometri pada motif wayang } \\
\text { - Translasi dan Refleksi Pada Motif Subahnale } \\
\text { - Transformasi geometri pada motif keker } \\
\text { - Transformasi geometri pada motif bintang empat } \\
\text { - Transformasi geometri pada motif alang/lumbung }\end{array}$ & $\begin{array}{l}\text { Konsep transformasi } \\
\text { geometri yang } \\
\text { ditemukan pada motif } \\
\text { tenun Sukarara Lombok } \\
\text { Tengah adalah konsep } \\
\text { refleksi (pencerminan) } \\
\text { dan translasi } \\
\text { (pergeseran) pada motif } \\
\text { wayang, subahnale, } \\
\text { keker, bintang empat, } \\
\text { dan alang/lumbung. }\end{array}$ \\
\hline Asri Fauzi1 & alam permainan dengklaq ditemukan beberapa unsur & Permainan tradisional \\
\hline
\end{tabular}




\begin{tabular}{|c|c|c|}
\hline $\begin{array}{l}\text { Ulfa } \\
\text { Lu'luilmaknun }\end{array}$ & $\begin{array}{l}\text { matematika yaitu: } \\
\text { - } \quad \text { terdapatnya unsur geometri bidang, hubungan antar } \\
\text { sudut jaring-jaring, kekongruenan, dan refleksi. } \\
\text { - Unsur matematika berupa konsep geometri bidang } \\
\text { dan konsep hubungan antar sudut. } \\
\text { - Logika matematika }\end{array}$ & $\begin{array}{l}\text { dengklaq tidak hanya } \\
\text { sebagai hiburan bagi } \\
\text { anak-anak, tetapi juga } \\
\text { dalam permainan ini } \\
\text { terdapat nilai edukasi } \\
\text { yang dapat membentuk } \\
\text { karakter anak. }\end{array}$ \\
\hline Muh. Yazid & 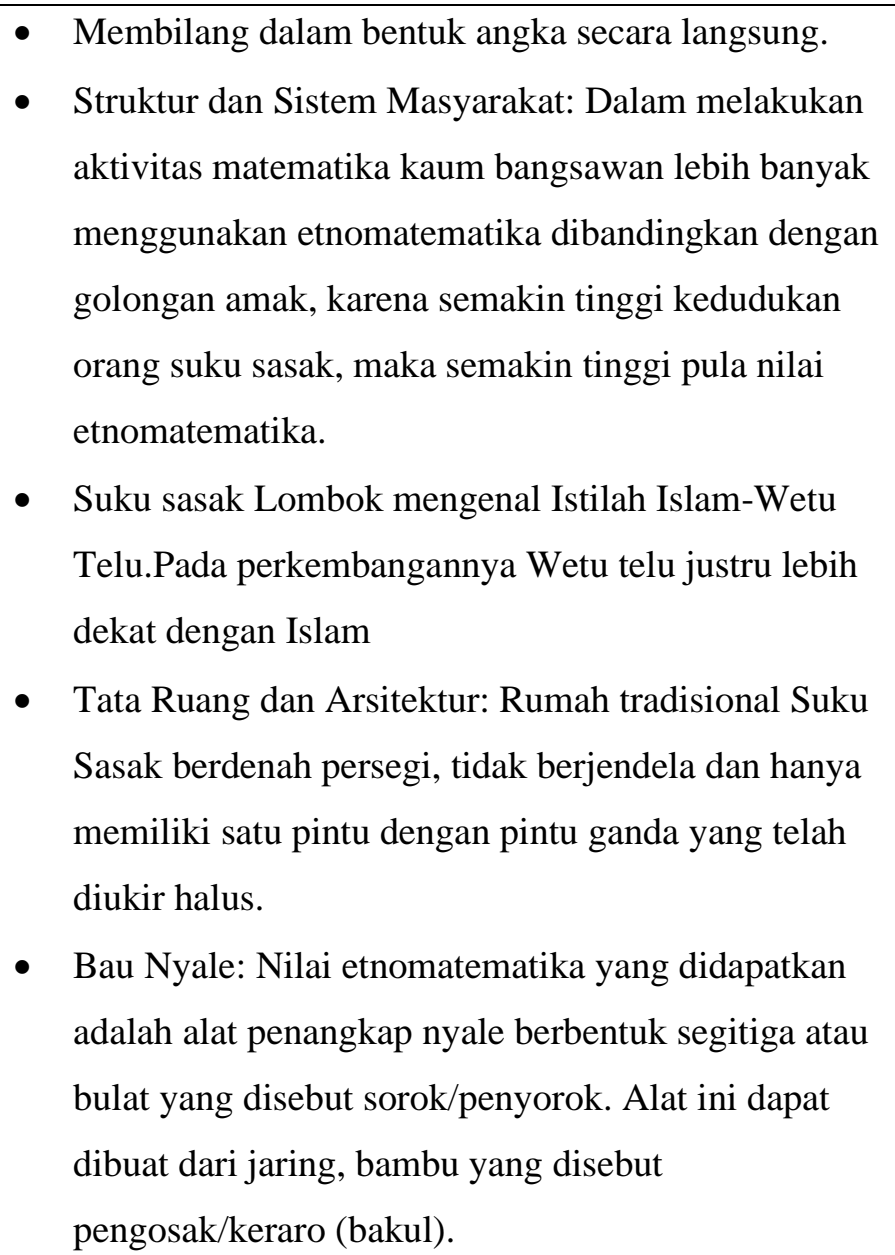 & $\begin{array}{l}\text { Terdapat konsep-konsep } \\
\text { matematika dalam } \\
\text { kehidupan sehari- } \\
\text { harinya menggunakan } \\
\text { etnomatematika. } \\
\text { Terbukti adanya bentuk } \\
\text { etnomatematika } \\
\text { masyarakat Lombok } \\
\text { yang tercermin melalui } \\
\text { berbagai hasil aktivitas } \\
\text { dan kreativitas } \\
\text { matematika yang } \\
\text { dimiliki dan berkembang } \\
\text { di masyarakat Lombok. }\end{array}$ \\
\hline $\begin{array}{l}\text { Asri Fauzi, } \\
\text { Heri Setiawan }\end{array}$ & $\begin{array}{l}\text { Motif kain tenun sesekan mengandung unsur } \\
\text { geometri berupa bangun datar yaitu persegi panjang, } \\
\text { segitiga, belah ketupat, jajargenjang, layang-layang, } \\
\text { bahkan terdapat konsep sudut, kesebangunan, dan } \\
\text { ellips lonjong } \\
\text { - Kerajinan bambu nyiru dan besek mengandung unsur } \\
\text { matematis yaitu konsep geometri pada bangun datar } \\
\text { yaitu lingkaran dan bangun ruang balok, kubus dan } \\
\text { prisma. } \\
\text { Tembolak (Tudung Saji) sebagai setengah lingkaran }\end{array}$ & $\begin{array}{l}\text { Berdasarkan kajian } \\
\text { terhadap bentuk } \\
\text { kerajinan tradisional } \\
\text { pada masyarakat Sasak } \\
\text { diperoleh unsur } \\
\text { etnomatematika yaitu } \\
\text { konsep geometri berupa } \\
\text { bangun datar dan } \\
\text { bangun ruang }\end{array}$ \\
\hline
\end{tabular}


Systematic Literature Review: Etnomatematika Kearifan Lokal Budaya Sasak, Muhammad Turmuzi, I Gusti Putu Sudiarta, I Gusti Putu Suharta

\begin{tabular}{|c|c|c|}
\hline $\begin{array}{l}\text { Sumayani, } \\
\text { Zaenuri, Iwan } \\
\text { Junaedi }\end{array}$ & $\begin{array}{l}\text { - Jaje ore biasanya berbentuk segitiga sedangkan jaje } \\
\text { - Jako biasanya berbentuk segi empat. } \\
\text { berbentuk segi empat } \\
\text { - Jaje renggi terbuat dari ketan yang dikukus dan gula } \\
\text { merah dan dibuat ada dalam bentuk segitiga atau segi } \\
\text { empat } \\
\text { - Jaje tujak atau jaje bangat terbuat dari ketan yang } \\
\text { dikukus dan di tujak (dihaluskan). Setelah halus baru } \\
\text { di bentuk dan di potong segi empat } \\
\text { - Jaje pangan terbuat dari tepung ketan, tepung beras, } \\
\text { santan dan gula merah, dan berbentuk segi empat } \\
\text { Jaje abuk terbuat dari beras ketan, gula merah, kelapa } \\
\text { parut dan berbentuk segi empat }\end{array}$ & $\begin{array}{l}\text { Makanan tradisional } \\
\text { suku sasak memiliki } \\
\text { bentuk model yang unik } \\
\text { berbentuk geometris. } \\
\text { Secara tidak sengaja } \\
\text { masyarakat suku Sasak } \\
\text { telah mempraktikkan } \\
\text { matematika dalam } \\
\text { kehidupan sehari-hari, } \\
\text { terlihat dari bentuk dan } \\
\text { model makanan yang } \\
\text { berbentuk segitiga, segi } \\
\text { empat dan lingkaran. } \\
\text { Selain itu bentuk dan } \\
\text { fungsi berbagai macam } \\
\text { makanan mengandung } \\
\text { nilai-nilai luhur. }\end{array}$ \\
\hline $\begin{array}{l}\text { Nur Hardiani, } \\
\text { Susilahudin } \\
\text { Putrawangsa }\end{array}$ & $\begin{array}{l}\text { - Satuan pengukuran suku sasak diantaranya: sekenjau, } \\
\text { sererik, secekel, segutus dan sedeud yang } \\
\text { menggambarkan konsep pecahan } \\
\text { - Secangkir, sekobok dan setebong menjelaskan } \\
\text { konsep pecahan, volume dan satuan berat. }\end{array}$ & $\begin{array}{l}\text { Budaya matematika } \\
\text { tidak hanya dalam } \\
\text { bentuk corak budaya } \\
\text { yang sifatnya kongkrit } \\
\text { (seperti bangunan, } \\
\text { bentuk motif, perkakas, } \\
\text { dan sebagainya), } \\
\text { melainkan juga dalam } \\
\text { bentuk pola pikir } \\
\text { (penalaran) yang } \\
\text { sifatnya abstrak }\end{array}$ \\
\hline $\begin{array}{l}\text { Asri Fauzi, } \\
\text { Aisa Nikmah } \\
\text { Rahmatih, } \\
\text { Muhammad } \\
\text { Sobri, } \\
\text { Radiusman, } \\
\text { Arif Widodo }\end{array}$ & $\begin{array}{l}\text { - Masjid kuno Bayan Beleq merupakan salah satu } \\
\text { bentuk atap menyerupai trapesium dan segitiga, } \\
\text { dinding masjid berbentuk persegi panjang. Di dalam } \\
\text { masjid terdapat } 4 \text { buah tiang, dan } 1 \text { bedug yang } \\
\text { berbentuk silinder/ tabung } \\
\text { - Bangunan tradisional bale tani yaitu bagian atap } \\
\text { berbentuk trapesium (tampak depan), segitiga (tampak } \\
\text { samping). Sedangkan, dinding dan pintu, berbentuk }\end{array}$ & $\begin{array}{l}\text { Melimpahnya produk } \\
\text { tradisional budaya sasak } \\
\text { sangat berperan penting } \\
\text { dalam penerapannya } \\
\text { sebagai media } \\
\text { pembelajaran, khusunya } \\
\text { pada pembelajaran } \\
\text { matematika di sekolah. }\end{array}$ \\
\hline
\end{tabular}




\begin{tabular}{|c|c|c|}
\hline & $\begin{array}{l}\text { persegi panjang } \\
\text { - Atap utama bale lumbung berbentuk setengah elips, } \\
\text { dan atap yang melebar ke samping berbentuk } \\
\text { trapesium. Pintu tempat memasukkan hasil panen } \\
\text { berbentuk persegi panjang } \\
\text { - Bentuk atap bale jajar sama seperti bangunan lainnya } \\
\text { yaitu berbentuk trapesium dan segitiga, memliki dua } \\
\text { buah pintu berbentuk persegi panjang } \\
\text { - gendang beleq adalah unsur geometri ruang yang } \\
\text { berbentuk silinder atau tabung. Diameter gendang } \\
\text { beleq tersebut adalah } 50 \text { cm dan panjang } 150 \mathrm{~cm} \\
\text { - Pada tradisi peresean terdapat pada perisai atau ende } \\
\text { yang berbentuk persegi panjang dengan ukuran } 40 \mathrm{x} \\
60 \mathrm{~cm} \\
\text { - Pada jajanan tradisional cerorot adalah unsur geometri } \\
\text { ruang berupa kerucut. }\end{array}$ & $\begin{array}{l}\text { Produk tradisional } \\
\text { budaya sasak juga } \\
\text { berperan dalam } \\
\text { pengenalan dan } \\
\text { pemeliharaan budaya } \\
\text { yang sudah mulai } \\
\text { ditinggalkan oleh } \\
\text { generasi muda }\end{array}$ \\
\hline $\begin{array}{l}\text { Al Kusaeri, } \\
\text { Muhamad } \\
\text { Habib Husnial } \\
\text { Pardi }\end{array}$ & $\begin{array}{l}\text { - Bagian penutup atas rombong gula gending berbentuk } \\
\text { lingkaran, bangun ruang kubus dan tabung } \\
\text { - Prane' merupakan alat pemintal benang yang } \\
\text { berbentuk segi delapan dan termasuk dalam segi } \\
\text { banyak beraturan } \\
\text { - Caraken merupakan peralatan dapur berbentuk pola } \\
\text { bangun ruang yang dibentuk oleh kubus satuan. }\end{array}$ & $\begin{array}{l}\text { Produk budaya yang } \\
\text { terdapat di desa } \\
\text { Kembang Kerang } \\
\text { Lombok Timur adalah } \\
\text { rombong gula gending, } \\
\text { parane, dan caraken, } \\
\text { melalui produk budaya } \\
\text { tersebut dapat } \\
\text { diidentifikasi objek } \\
\text { matematika berupa } \\
\text { bangun datar dan } \\
\text { bangun ruang. }\end{array}$ \\
\hline Sri Supiyati & 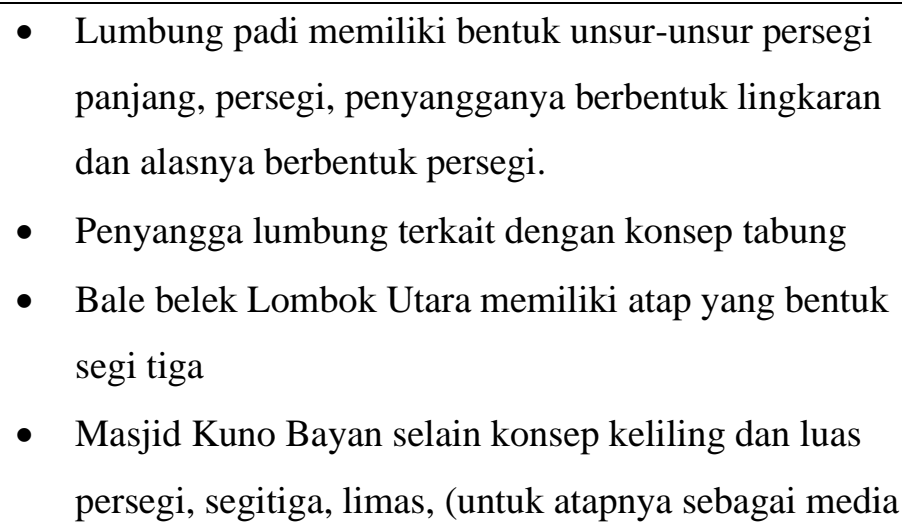 & $\begin{array}{l}\text { Ethnomathematics } \\
\text { memiliki tempat yang } \\
\text { penting dalam } \\
\text { pendidikan matematika } \\
\text { dalam perspektif budaya } \\
\text { sasak. Hal ini } \\
\text { dimungkinkan untuk } \\
\text { menyadarkan siswa }\end{array}$ \\
\hline
\end{tabular}




\begin{tabular}{|l|l|l|}
\hline & $\begin{array}{l}\text { dalam menghitung luas permukaan dan volume dan } \\
\text { bagian bawah berbentuk limas terpancung dan } \\
\text { alasnya berbentuk persegi) }\end{array}$ & $\begin{array}{l}\text { untuk mendapatkan } \\
\text { bagaimana masyarakat } \\
\text { melakukan aktivitas }\end{array}$ \\
$\begin{array}{l}\text { Gendang belek berbentuk tabung, penutup gendang } \\
\text { berbentuk lingkaran. Mengidentifikasi unsur, } \\
\text { keliliing dan luas dari lingkaran. Volume Benda } \\
\text { Putar. Menentukan luas permukaan. }\end{array}$ & $\begin{array}{l}\text { madaya mereka sendiri } \\
\text { dan pikiran matematika } \\
\text { Gerabah di Banyumulek Lombok Barat dan Penakak } \\
\text { di Lombok Timur memiliki bentuk yang sangat } \\
\text { banyak, seperti lingkaran, tabung, kerucut dan bisa } \\
\text { untuk alat peraga menentukan integral. }\end{array}$ & $\begin{array}{l}\text { mengembangkan model } \\
\text { kurikulum } \\
\text { ethnomathematica dalam } \\
\text { program pendidikan }\end{array}$ \\
\hline
\end{tabular}

Dalam tabel 2. di atas dapat dijelaskan konsep matematika yang ada dalam budaya sasak adalah sebagai berikut: Untuk Artikel yang ditulis oleh (Sri Supiyati, Farida Hanum, Jailani, 2019). Konsep matematika ditemukan pada bentuk arsitektur bangunan suku Sasak yaitu pada masjid, rumah dan atap rumah bale tani, kubah lumbung, ruang dalem bale (kamar tidur), ukiran pada pintu rumah dan pintu gerbang. Konsep matematikanya meliputi: pencerminan, segitiga, persegi dan persegipanjang, simetris, trapezium dan prisma. Untuk artikel dari (Sutarto, Intan Dwi Hastuti dan Sri Supiyati, 2021), konsep matematika ditemukan pada motif Tenun daerah Sukarara Lombok Tengah meliputi: transformasi geometri, refleksi (pencerminan) dan translasi (pergeseran). Konsep matematika pada motif tenun juga banyak ditemukan pada etnomatematika pada daerah lain seperti: motif batik Paoman Indramayu (Sudirman et al., 2018, p. 27), pola batik tenun (ATBM) khas Kota Kediri (Samijo \& Yohanie, 2017, p. 134), Tinjauan Aspek Geometris Batik Lebak Provinsi Banten (Subekhi et al., 2021, p. 81), Motif Kain Tenun Sumba Barat (Ledi et al., 2020, p. 87), kain tenun songket Suku Melayu Sambas (Panjaitan et al., 2021, p. 19).

Untuk artikel yang ditulis oleh (Asri Fauzi \& Ulfa Lu'luilmaknun, 2019) konsep matematika meliputi unsur geometri bidang, hubungan antar sudut jaring-jaring, kekongruenan, dan refleksi. Konsep ini ditemukan pada permainan tradisional dengklak, yaitu permainan dengan cara melompati petak-petak pada bidang datar dengan satu kaki. Petak-petak yang ada pada permainan dengklaq dapat berbentuk berbagai jenis geometri bidang seperti persegi, segitiga, dan setengah lingkaran. Ini membuktikan bahwa permainan tradisional dengklaq memiliki unsur matematika. Kajian matematika pada permainan tradisional dapat ditemukan pula pada budaya lain seperti etnomatematika pada permainan tradisional engklek dan gasing khas kebudayaan Sunda (Febriyanti et al., 2018, p. 1), eksplorasi konsep etnomatematika dalam permainan tradisional kelereng pada anak masyarakat Kota Ende (Mei et al., 2020, p. 29), eksplorasi etnomatematika konsep operasi hitung dalam Permainan Tradisional Kempreng (Susanti, 2020, p. 1). Pada artikel yang ditulis oleh (Muh. Yazid, 2018) ini 
lebih membahas budaya Sasak yang berkaitan dengan penanaman karakter budaya. Karakter yang dimaksudkan adalah Islam Waktu Telu, Tata Ruang dan Arsitektur seperti yang sudah di bahas oleh tulisan (Sri Supiyati et. al, 2019), budaya Bau Nyale merupakan tradisi turun temurun. Dalam tradisi ini, ribuan orang menangkap cacing laut di sepanjang pantai Pulau Lombok. Cacing-cacing laut ini dikenal dengan sebutan nyale, yang dipercaya sebagai jelmaan Putri Mandalika. Mandalika dikenal sebagai putri cantik yang memilih menceburkan diri ke laut lepas, menghindari peperangan antar pangeran yang memperebutkan dirinya. Legenda Putri Mandalika ini dikenal hampir di seluruh penjuru Pulau Lombok. Meskipun belum ada lontar Lombok yang ditemukan mengenai Mandalika yang melegenda tersebut. (Fazalani, 2018, pp. 164-165).

Pada artikel yang ditulis oleh (Asri Fauzi \& Heri Setiawan, 2020) pembahasan berkaitan dengan motif kain tenun sesekan seperti pada artikel yang ditulis oleh (Sutarto, et.al, 2021), pada motif kain tenun ini mengandung unsur geometri berupa bangun datar yaitu persegi panjang, segitiga, belah ketupat, jajargenjang, layang-layang, bahkan terdapat konsep sudut, kesebangunan, dan ellips lonjong, selain itu artikel ini juga membahas tentang kerajinan bambu nyiru dan besek yang mengandung unsur matematis yaitu konsep geometri pada bangun datar yaitu lingkaran dan bangun ruang balok, kubus dan prisma dan tembolak (tudung saji) sebagai setengah lingkaran. Penelitian serupa tentang kerajianan bambu sudah pernah dilakukan yaitu oleh (Wahyuni, 2021, p. 35) Analisis Etnomatematika Pada Kerajinan Anyaman Bambu Terhadap Pemebelajaran Matematika di Kabupaten Sukabumi. Penelitian ini menyimpulkan bahwa terdapat konsep matematika pada kerajinan anyaman bambu yaitu konsep lingkaran, dimensi tiga dan segi empat. Demikian juga penelitian oleh Puspadewi \& Putra (2014, p. 80) membahas etnomatematika di balik kerajinan anyaman Bali.

Selanjutnya untuk artikel yang ditulis oleh (Sumayani, Zaenuri \& Iwan Junaedi, 2020), pembahasan difokuskan pada makanan tradisional Suku Sasak yang meliputi Jaje ore, Jaje opakopak, Jaje renggi, Jaje tujak atau jaje bangat, Jaje pangan dan jaje abuk. Konsep matematika yang ditemukan adalah segi empat. Banget atau biasa juga disebut jaje Reket. Banget merupakan jajan khas Lombok yang terbuat dari ketan yang dikukus. Sedangkan Jaje Reket terbuat dari Banget yang dibungkus menggunakan daun pisang dengan bentuk panjang. Jaje Reket bisa terbuat dari beras ketan putih maupun beras ketan hitam. Jaje Reket sangat nikmat jika dijadikan Timbung dengan cara dibakar. Aroma ketan yang dibungkus daun pisang menjadikan jajan yang satu ini begitu menggugah selera. Timbung banyak dijual di pasar-pasar tradisional Lombok. Penelitian lain yang terkait dengan makanan tradisional diantaranya Etnomatematika Pada Bentuk Jajanan Pasar di Daerah Istimewa Yogyakarta (Huda, 2018, p. 217), Etnomatematika: Makanan Tradisional Bugis Sebagai Sumber Belajar Matematika (Pathuddin \& Raehana, 2019, p. 307) dan Studi etnomatematika pada makanan tradisional Cilacap (Choeriyah et al., 2020, p. 210).

Artikel tulisan dari (Nur Hardiani \& Susilahudin Putrawangsa, 2019) berkaitan dengan satuan pengukuran masyarakat Sasak. Bila pada satuan umumnya kita mengenal satuan panjang seperti meter (m), km, cm, mil, dan seterusnya, satuan volume seperti liter, cc, meter kubik dan seterusnya,maka di 
masyarakat sasak dikenal juga satuan pengukuran seperti sekenjau, sererik, secekel, segutus dan sedeud yang menggambarkan konsep pecahan, secangkir, sekobok dan setebong menjelaskan konsep pecahan, volume dan satuan berat. Artikel tulisan dari (Asri Fauzi, Aisa Nikmah Rahmatih, Muhammad Sobri, Radiusman \& Arif Widodo, 2020) membahas tentang arsitektur bangunan kuno masyarakat Sasak dan makanan khas Sasak, hal ini serupa dengan yang dibahas pada artikel (Sri Supiyati, et.al, 2019) dan artikel oleh (Sumayani, et.al, 2020). Selain membahas bangunan tradisional masyarakat Sasak, artikel ini juga membahas tentang kebudayaan masyarakat Sasak yang sangat popular di kalangan masyarakat Sasak itu sendiri yaitu Tradisi Peresean dan alat musik Gendang Belek. Konsep matematika yang dapat ditemukan pada peresean dan Gendang Belek adalah mengidentifikasi unsur, keliliing dan luas dari lingkaran, volume benda putar, menentukan luas permukaan, persegi, persegipanjang, garis, lingkaran dan konsep tabung.

Selain keindahan alam, Lombok punya banyak tradisi yang menarik untuk diketahui. Salah satunya adalah Peresean. Pada zaman Kerajaan Mataram dulu, pemuda Suku Sasak yang ingin bergabung menjadi prajurit harus mengikuti Peresean. Acara itu terdiri dari pepadu yang dilengkapi dengan tongkat rotan (penjalin) dan perisai dari kulit kerbau yang tebal dan keras (ende). Peresesan dilakukan untuk melatih ketangkasan, ketangguhan dan keberanian para pemuda. (Solikatun et al., 2018 , p. 3). Peresean juga diyakini oleh masyarakat setempat sebagai ritual meminta hujan saat musim kemarau panjang tiba. Kini, Peresean menjadi tradisi budaya yang diminati oleh wisatawan. Sedangkan kesenian Gdendang Belek adalah tari tradisional dan musik orkestra yang berkembang di pulau Lombok. Disebut gendang beleq karena penari menggunakan gendang berukuran besar (sasak: beleq=besar) sebagai property atau salah satu alat musiknya adalah gendang yang ukurannya sangat besar dibandingkan dengan gendang pada umumnya. Pada awalnya, gendang beleq hanyalah alat musik yang mengiringi prajurit saat akan berjuang ke medan perang. Suara yang dihasilkan dipercaya membuat para prajurit menjadi lebih berani untuk berkorban membela kerajaan. Akan tetapi pada zaman sekarang gendang beleq digunakan untuk mengiringi iringan pengantin dan digunakan sebagai hiburan untuk suku Sasak untuk mempererat rasa persaudaraan dan dipertujukkan pada saat acara kebudayaan seperti acara vestipal.(Fazalani, 2020, p. 257).

Selanjutnya untuk artikel yang ditulis oleh (Al Kusaeri \& Muhamad Habib Husnial Pardi, 2019) membahas alat musik tradisional Sasak yang sekaligus berfungsi sebagai tempat wadah menaruh gula (manisan) untuk jualan keliling sambil berjalan kaki. Alat musik ini diberi nama rombong gula gending. Konsep matematika pada rombong gula gending ini adalah lingkaran, bangun ruang kubus dan tabung. Selain itu artikel ini juga membahas tentang 'Prane' merupakan alat pemintal benang yang berbentuk segi delapan dan termasuk dalam segi banyak beraturan serta Caraken merupakan peralatan dapur berbentuk pola bangun ruang yang dibentuk oleh kubus satuan. Yang terakhir adalah artikel tulisan dari (Sri Supiyati, 2016) yang membahas tentang matematika dalam perspektif Budaya Sasak. Fokus pembahasan artikel ini adalah bangunan tradisional masyarakat Sasak dan alat music Gendang Belek. Artikel ini juga membahas tentang kerajinan 
Gerabah di Banyumulek Lombok Barat dan Penakak di Lombok Timur. Konsep matematika pada kerajinan grabah ini meliputi lingkaran, tabung, kerucut dan bisa untuk alat peraga menentukan integral. Gerabah Tinggang merupakan salah satu bentuk kerajinan gerabah khas yang ada di Desa Banyumulek, Kecamatan Kediri, Lombok Barat. Gerabah Tinggang memiliki bentuk dan ukuran yang relatif lebih besar dan tinggi yang dapat mencapai 1-2 meter. Alat dan bahan yang digunakan dalam proses pembuatan gerabah Tinggang hampir sama dengan alat dan bahan yang digunakan pada gerabah biasanya. Yang membedakan gerabah Tinggang dan gerabah yang lain adalah terletak pada proses pembuatannya yaitu gerabah Tinggang lebih mengutamakan keseimbangan gerabah agar mendapat ukuran dan bentuk sesuai yang diinginkan. (Dewi et al., 2015, p. 8).

Dari uraian di atas dapat dibuat rangkuman topik bahasan dari masing-masing artikel yaitu meliputi: Arsitektur Bangunan Tradsional Suku Sasak, Kerajinan Kain Tenun, Permainan Tradisional, Penanaman Karakter Budaya, Satuan Pengukuran, Alat Musik Tradisional Sasak, Makanan Khas Tradisi Sasak dan Kerajinan Gerabah. Untuk uraian lengkapnya dapat dilihat pada tabel 3.

Tabel 3. Rangkuman Topik Pembahasan

\begin{tabular}{|c|c|c|}
\hline No & Topik Bahasan & Artikel yang Terkait \\
\hline 1 & Arsitektur Bangunan Tradsional Suku Sasak & $\begin{array}{l}\text { (Sri Supiyati, Farida Hanum, Jailani, 2019), } \\
\text { (Muh. Yazid, 2018), (Asri Fauzi, Aisa } \\
\text { Nikmah Rahmatih, Muhammad Sobri, } \\
\text { Radiusman \& Arif Widodo, 2020), (Sri } \\
\text { Supiyati, 2016) }\end{array}$ \\
\hline 2 & Kerajinan Kain Tenun & $\begin{array}{l}\text { (Sutarto, Intan Dwi Hastuti dan Sri Supiyati, } \\
\text { 2021), (Asri Fauzi \& Heri Setiawan, 2020) }\end{array}$ \\
\hline 3 & Permainan Tradisional & (Asri Fauzi \& Ulfa Lu'luilmaknun, 2019) \\
\hline 4 & Penanaman Karakter Budaya & (Muh. Yazid, 2018) \\
\hline 5 & Satuan Pengukuran & $\begin{array}{l}\text { (Nur Hardiani \& Susilahudin Putrawangsa, } \\
\text { 2019) }\end{array}$ \\
\hline 6 & Alat Musik Tradisional Sasak & $\begin{array}{l}\text { (Asri Fauzi, Aisa Nikmah Rahmatih, } \\
\text { Muhammad Sobri, Radiusman \& Arif } \\
\text { Widodo, 2020), (Al Kusaeri \& Muhamad } \\
\text { Habib Husnial Pardi, 2019) }\end{array}$ \\
\hline 7 & Makanan Khas Tradisi Sasak & $\begin{array}{l}\text { (Sumayani, Zaenuri \& Iwan Junaedi, 2020), } \\
\text { (Asri Fauzi, Aisa Nikmah Rahmatih, } \\
\text { Muhammad Sobri, Radiusman \& Arif } \\
\text { Widodo, 2020) }\end{array}$ \\
\hline 8 & Kerajinan Gerabah & (Sri Supiyati, 2016) \\
\hline
\end{tabular}


Systematic Literature Review: Etnomatematika Kearifan Lokal Budaya Sasak, Muhammad Turmuzi, I Gusti Putu Sudiarta, I Gusti Putu Suharta

\section{KESIMPULAN}

Kesimpulan penelitian Analisis Meta ini adalah dari hasil penelusuran 10 artikel yang relevan terkait topik kajian pembahasan Enomatematika Budaya Sasak meliputi ragam pembahasan Arsitektur Bangunan Tradsional Suku Sasak, Kerajinan Kain Tenun, Permainan Tradisional, Penanaman Karakter Budaya, Satuan Pengukuran, Alat Musik Tradisional Sasak, Makanan Khas Tradisi Sasak dan Kerajinan Gerabah. Sedangkan temuan konsep matematika dari topik pembahasan tersebut antara lain Geometri Bidang Datar, Bangun Ruang Geometri, Konsep Transformasi geometri, Pengukuran, Volume Benda Putar, Keliling dan Luas Bidang Datar.

Saran dan rekomendasi dari hasil penelitian ini adalah dengan diketahuinya konsep-konsep matematika yang berkaitan dengan kearifan lokal Budaya Sasak maka dapat dikembangkan proses pembelajaran berbasis Etnomatematika Budaya sasak dalam pembelajaran matematika di sekolah. Pengembangan pembelajaran dapat berupa pengembangan modul pembelajaran berbasis etnomatematika, pengembangan media pembelajaran, model pembelajaran, pendekatan dan metode pembelajaran yang berbasis etnomatematika.

\section{REFERENSI}

Aliyah, U., \& Mulawarman, M. (2020). Kajian Systematic Literature Review (SLR) Untuk Mengidentifikasi Dampak Terorisme, Layanan Konseling dan Terapi Trauma Pada Anak-Anak. ISLAMIC COUNSELING Jurnal Bimbingan Konseling Islam, 4(2), 209. https://doi.org/10.29240/jbk.v4i2.1759

Ascher, M., \& Ambrosio, U. A. N. D. (1994). Ethnomathematics : a Dialogue. 2, 36-43.

Barta, J., \& Shockey, T. (2006). The Mathematical Ways of an Aboriginal People: The Northern Ute. The Journal of Mathematics and Culture, 1(1), 79-89.

Bishop, A. J. (1994). Cultural conflicts in mathematics education: developing a research agenda. FLM Publishing Association, Vancouver, British Columbia, Canada, 14(2), 15-18.

Buyung, \& Hendriana, E. C. (2020). KEMAMPUAN PEMAHAM A N KONSEP MATEMATIKA MAHASISWA MENGGUNAKAN LEMBAR KERJA MAHASISWA. MES: Journal of Mathematics Education and Science, 6(1), 1-9. https://jurnal.uisu.ac.id/index.php/mesuisu Choeriyah, L., Nusantara, T., Qohar, A., \& Subanji. (2020). Studi Etnomatematika pada Makanan Tradisional Cilacap. AKSIOMA : Jurnal Matematika Dan Pendidikan Matematika, 11(2), 210218. http://journal.upgris.ac.id/index.php/aksioma/article/view/5980/3690

Dewi, N. K., Suartini, L., \& Rediasa, I. N. (2015). Kerajinan Gerabah Tinggang di Desa Banyumulek, Kecamatan Kediri, Lombok Barat. JURNAL PENDIDIKAN SENI RUPA UNDIKSHA, 5(1), 1-9. Fadillah, R., Giatman, M., \& Muskhir, M. (2021). Meta Analysis : Efektivitas Penggunaan Metode Proyect Based Learning Dalam Pendidikan Vokasi. 4(1), 138-146.

Fazalani, R. (2018). Tradisi Bau Nyale Terhadap Nilai Multikultural Pada Suku Sasak. FON ; Jurnal Pendidikan Bahasa Dan Sastra Indonesia, 13, 162-171. 
Fazalani, R. (2020). Kesenian Gendang Belek Masyarakat Suku Sasak Sebagai Budaya Tradisional. Lingua Franca: Jurnal Bahasa, Sastra, Dan Pengajarannya, 4(2), 256-268.

Febriyanti, C., Prasetya, R., \& Irawan, A. (2018). Etnomatematika Pada Permainan Tradisional Engklek Dan Gasing Khas Kebudayaan Sunda. Barekeng: Jurnal Ilmu Matematika Dan Terapan, 12(1), 1. https://doi.org/10.30598/vol12iss1pp1-6ar358

Hardiarti, S. (2017). Etnomatematika : Aplikasi Bangun Datar. Aksioma, 8(2), 99-110.

Huda, N. T. (2018). Etnomatematika Pada Bentuk Jajanan Pasar di Daerah Istimewa Yogyakarta. $\begin{array}{lllll}\text { JNPM (Jurnal Nasional Pendidikan } & \text { Matematika), } & \text { 2(2), }\end{array}$ https://doi.org/10.33603/jnpm.v2i2.870

Kamarusdiana, K. (2019). Studi Etnografi Dalam Kerangka Masyarakat Dan Budaya. SALAM: Jurnal Sosial Dan Budaya Syar-I, 6(2), 113-128. https://doi.org/10.15408/sjsbs.v6i2.10975

Ledi, F., Kusmanto, B., \& Agustito, D. (2020). Identifikasi Etnomatematika pada Motif Kain Tenun Sumba Barat. UNION: Jurnal Ilmiah Pendidikan Matematika, 8(1), 87. https://doi.org/10.30738/union.v8i1.5338

Leniati, B., \& Indarini, E. (2021). Meta Analisis Komparasi Keefektifan Model Pembelajaran Kooperatif Tipe Jigsaw dan TSTS (Two Stay Two Stray) Terhadap Kemampuan Berpikir Kritis pada Pembelajaran Matematika Siswa Sekolah Dasar. Mimbar Ilmu, 26(1), 149. https://doi.org/10.23887/mi.v26i1.33359

Mei, M. ., Seto, S. ., \& Wondo, M. T. S. (2020). Eksplorasi Konsep Etnomatematika dalam Permainan Tradisional Kelereng pada Anak Masyarakat Kota Ende. EduMatSains, 5(1), 29-38.

Panjaitan, S., Hartoyo, A., \& Fitriawan, D. (2021). Eksplorasi Etnomatematika Kain Tenun Songket Suku Melayu Sambas. Jurnal AlphaEuclidEdu, 2(1), 19-31. https://jurnal.untan.ac.id/index.php/AlphaEuclidEdu/article/view/47890

Pathuddin, H., \& Raehana, S. (2019). Etnomatematika: Makanan Tradisional Bugis Sebagai Sumber Belajar Matematika. MaPan, 7(2), 307-327. https://doi.org/10.24252/mapan.2019v7n2a10

Pinxten, R. (1994). Ethnomathematics and Its Practice. For the Learning of Mathematics, 14(2), 2325.

https://biblio.ugent.be/publication/242364\%0Ahttps://eric.ed.gov/?id=EJ502147\%0Ahttps://ww w.jstor.org/stable/info/40248111\%0Ahttps://lens.org/107-460-662-766-521

Prahmana, R. C. I., Yunianto, W., Rosa, M., \& Orey, D. C. (2021). Ethnomathematics: Pranatamangsa system and the birth-death ceremonial in yogyakarta. Journal on Mathematics Education, 12(1), 93-112. https://doi.org/10.22342/JME.12.1.11745.93-112

Puspadewi, K. R., \& Putra, I. G. N. (2014). Etnomatematika di Balik Kerajinan Anyaman Bali. Jurnal Matematika, 4(2), 80-89.

Putra, A., \& Afrilia, K. (2020). Systematic Literature Review: Penggunaan Kahoot Pada Pembelajaran Matematika. Jurnal Ilmiah Pendidikan Matematika Al Qalasadi, 4(2), 110-122. https://doi.org/10.32505/qalasadi.v4i2.2127 
Systematic Literature Review: Etnomatematika Kearifan Lokal Budaya Sasak, Muhammad Turmuzi, I Gusti Putu Sudiarta, I Gusti Putu Suharta

Rachmawati, I. (2012). Eksplorasi Etnomatematika Masyarakat Sidoarjo. MATHEdunesa, 1(1).

Rahayu, A. P., Snae, M., \& Bani, S. (2020). Etnomatematika Pada Kain Tenun Lipa Kaet. MEGA: Jurnal Pendidikan Matematika, 1(1), 16-24. https://ejournal.unmuhkupang.ac.id/index.php/mega/article/view/178

Rosa, M., \& Clark, D. (2011). Ethnomathematics: the cultural aspects of mathematics. Revista Latinoamericana de Etnomatemática: Perspectivas Socioculturales de La Educación Matemática, 4(2), 32-54.

Samijo, S., \& Yohanie, D. D. (2017). Pengaruh model pembelajaran kontekstual berbasis etnomatematika pada pola batik tenun (ATBM) khas Kota Kediri terhadap kemampuan refleksi dan simetri mahasiswa semester 2 Prodi Pendidikan Matematika UNP Kediri. Jurnal Math Educator Nusantara: Wahana Publikasi Karya Tulis Ilmiah Di Bidang Pendidikan Matematika, 3(2), 135. https://doi.org/10.29407/jmen.v3i2.11975

Solikatun, Karyadi, L. W., \& Wijayanti, I. (2018). Eksistensi Seni Pertunjukan Peresean pada Masyarakat Sasak Lombok. SANGKEP: Jurnal Kajian Sosial Keagamaan, 2(1), 1-12.

Subekhi, A. I., Nindiasari, H., \& Sukirwan, S. (2021). Etnomatematika: Tinjauan Aspek Geometris Batik Lebak Provinsi Banten. JNPM (Jurnal Nasional Pendidikan Matematika), 5(1), 81. https://doi.org/10.33603/jnpm.v5i1.3577

Sudiarta, I. G. P. (2008). Meta Analisis Penelitian Pendidikan Matematika. In Universitas Pendidikan Ganesha. Singaraja Bali.

Sudirman, S., Son, A. L., \& Rosyadi, R. (2018). Penggunaan Etnomatematika Pada Batik Paoman Dalam Pembelajaran Geomteri Bidang di Sekolah Dasar. IndoMath: Indonesia Mathematics Education, 1(1), 27. https://doi.org/10.30738/indomath.v1i1.2093

Supiyati, S., Hanum, F., \& Jailani. (2019). Ethnomathematics in sasaknese architecture. Journal on Mathematics Education, 10(1), 47-57. https://doi.org/10.22342/jme.10.1.5383.47-58

Susanti, E. (2020). Eksplorasi Etnomatematika Konsep Operasi Hitung dalam Permainan Tradisional Kempreng. Suska Journal of Mathematics Education, 6(1), 1-8. http://ejournal.uinsuska.ac.id/index.php/SJME/article/view/10025

Triandini, E., Jayanatha, S., Indrawan, A., Werla Putra, G., \& Iswara, B. (2019). Metode Systematic Literature Review untuk Identifikasi Platform dan Metode Pengembangan Sistem Informasi di Indonesia. Indonesian Journal of Information Systems, 1(2), 63. https://doi.org/10.24002/ijis.v1i2.1916

Wahyuni, N. S. (2021). Analisis Etnomatematika Pada Kerajinan Anyaman Bambu Terhadap Pemebelajaran Matematika di Kabupaten Sukabumi. Jurnal Peka, 4(2), 35-40. https://doi.org/10.37150/jp.v4i2.819

Windiani, \& Nurul, F. (2016). Menggunakan Metode Etnografi dalam Penelitian Sosial. Dimensi Jurnal Sosiologi, 9(2), 87-92. 